\title{
Erratum to: Influence of statin treatment on coronary atherosclerosis visualised using multidetector computed tomography
}

\author{
Hans Hoffmann • Katja Frieler • Peter Schlattmann • \\ Bernd Hamm • Marc Dewey
}

Published online: 3 March 2011

(C) European Society of Radiology 2011

Erratum to: Eur Radiol (2010) 20: 2824-2833

DOI 10.1007/s00330-010-1880-x

Unfortunately, an error has been introduced into the original publication during preparation of the printed version after proof reading by the authors.

In "Statistical analysis", the correct sentence must read:

Thus, the following functional dependence of the growth rate was analysed: $\left(\operatorname{trans} V_{1}-\operatorname{trans} V_{0}\right) /\left(t_{1}-t_{0}\right)=\beta_{0}+$ $\beta_{1} \times \operatorname{trans} V_{0}+\beta_{2} \times$ statin dosage equivalent.

The online version of the original article can be found at http://dx.doi. org/10.1007/s00330-010-1880-x.

H. Hoffmann • B. Hamm • M. Dewey

Department of Radiology, Charité, Medical School,

Freie Universität Berlin and Humboldt-Universität zu Berlin,

Charitéplatz 1,

Berlin, Germany

H. Hoffmann

Department of Cardiology, Angiology, and Pulmonology,

Klinikum Brandenburg,

Brandenburg an der Havel, Germany

K. Frieler $\cdot$ P. Schlattmann

Department of Medical Statistics, Charité, Medical School, Freie Universität Berlin and Humboldt-Universität zu Berlin,

Berlin, Germany

K. Frieler

Potsdam Institut für Klimaforschung,

Potsdam, Germany

M. Dewey $(\triangle)$

Department of Radiology, Charité - Universitätsmedizin Berlin, Freie Universität Berlin and Humboldt-Universität zu Berlin,

Charitéplatz 1,

P.O. Box 10098, 10117 Berlin, Germany

e-mail: marc.dewey@charite.de 